\section{Flowering, Stem Extension Growth, and Cutting Yield of Foliage Annuals in Response to Photoperiod}

\author{
Kellie J. Walters, Allison A. Hurt, and Roberto G. Lopez ${ }^{\mathbf{1}}$ \\ Department of Horticulture, Michigan State University, 1066 Bogue Street, \\ East Lansing, MI 48824
}

Additional index words. Alternanthera, Iresine herbstii, LEDs, Solanum jasminoides, stock plant, Strobilanthes dyerianus

\begin{abstract}
Foliage annuals are primarily grown for the aesthetic appeal of their brightly colored, variegated, or patterned leaves rather than for their flowers. Once foliage annuals become reproductive, vegetative growth of many species diminishes or completely ceases and plants can become unappealing. Therefore, the objectives of this study were to quantify how growth and development during production and stock plant cutting yield of bloodleaf (Iresine herbstii), Joseph's coat (Alternanthera sp.) 'Brazilian Red Hots' and 'Red Threads', Persian shield (Strobilanthes dyerianus), and variegated potato vine (Solanum jasminoides) are influenced by photoperiod and night interruption (NI) lighting with or without far-red (FR) radiation. Photoperiods consisted of a 9-hour short day (SD) or a 9-hour SD extended to 10, 12, 13, 14, or 16 hours with red (R):white $(W)$ :FR light-emitting diode (LED) lamps ( $R: F R=0.8)$ providing a total photon flux density $(T P F D)$ of $\approx 2 \mu \mathrm{mol} \cdot \mathrm{m}^{-2} \cdot \mathrm{s}^{-1}$ of radiation. In addition, two treatments consisted of a 9-hour SD with a 4-hour NI from lamps containing the same R:W:FR or R:W LEDs (R: FR = 37.4). Bloodleaf plant and Joseph's coat 'Brazilian Red Hots' and 'Red Threads' developed inflorescences or flowers under photoperiods $\leq 12$ to 13 hours and were classified as obligate SD plants. Under LEDs providing R:W:FR radiation, stem elongation of reproductive bloodleaf and Joseph's coat 'Brazilian Red Hots' and 'Red Threads' increased as photoperiod increased from 9 to 12 hours. In addition, stem elongation of bloodleaf, Joseph's coat 'Brazilian Red Hots' and 'Red Threads', and Persian shield and growth index $(G I=\{$ plant height $+[($ diameter $1+$ diameter 2$) / 2]\} / 2)$ of bloodleaf and Persian shield was significantly greater under NI with FR radiation than without FR radiation. Fewer or no cuttings were harvested from Joseph's coat 'Brazilian Red Hots' and 'Red Threads' under photoperiods $\leq 12$ or $\leq 13$ hours, respectively. To prevent unwanted flowering of bloodleaf plant and Joseph's coat, a photoperiod $\geq 14$ hours or 4-hour NI must be maintained with LEDs providing either R:W or R:W:FR radiation, however; stem elongation is significantly reduced under $R: W$ LEDs.
\end{abstract}

Foliage annuals are an increasingly important part of the U.S. floriculture industries' $\$ 1.86$ billion bedding and garden plant sector (USDA, 2016). Unlike most bedding and garden plants, they are primarily grown for the aesthetic appeal of their brightly colored, variegated, or patterned leaves rather than for their flowers (Walters et al., 2017). Production of foliage annuals should theoretically be easier, as growers do not have to schedule flowering plants for specific market dates. However, when foliage annuals

\footnotetext{
Received for publication 4 Dec. 2018. Accepted for publication 10 Jan. 2019.

This work was supported by the U.S. Department of Agriculture, National Institute of Food and Agriculture, Hatch project MICL02472.

We gratefully acknowledge Kalamazoo Specialty Plants for plant material and funding; Philips Lighting for LED flowering lamps; GreenCare Fertilizer for fertilizer; and Nathan DuRussel for technical assistance. The use of trade names in this publication does not imply endorsement by Michigan State University of products named nor criticism of similar ones not mentioned.

${ }^{1}$ Corresponding author. E-mail: rglopez@msu.edu.
}

hastened if plants are grown under a certain photoperiod.

Photoperiodic responses are regulated by phytochrome, a photoreceptor. When plants perceive R (600-700 $\mathrm{nm}$ ) radiation, phytochrome converts to the biologically active form $\left(\mathrm{P}_{\mathrm{FR}}\right)$. In contrast, when FR $(700-800 \mathrm{~nm})$ radiation is perceived, phytochrome is converted to the inactive form $\left[\left(\mathrm{P}_{\mathrm{R}}\right)\right.$ Sager et al., 1988]. In general, during the night, $\mathrm{P}_{\mathrm{FR}}$ gradually converts to $P_{R}$. When the skotoperiod is long, the greater conversion to $\mathrm{P}_{\mathrm{R}}$ generally promotes flowering of SD plants, whereas shorter skotoperiods result in greater $\mathrm{P}_{\mathrm{FR}}$, promoting flowering of $\mathrm{LD}$ plants (Craig and Runkle, 2016).

In LD plants, FR-deficient environments often delay flowering (Kim et al., 2000; van Haeringen et al., 1998), but providing photoperiodic lighting with only FR is not consistently effective at promoting flowering (Craig and Runkle, 2016; Nishidate et al., 2012). Therefore, a combination of $R$ and $F R$ radiation can be used for photoperiodic control of LD plants. Similarly, providing only FR radiation for NI lighting also is perceived as an SD in SD plants and is not effective at inhibiting flowering, whereas a combination of $\mathrm{R}$ and FR radiation is effective (Craig and Runkle, 2013). However, flowering of SD plants also can be inhibited with NI lighting providing only $\mathrm{R}$ radiation (Borthwick et al., 1952; Cathey and Borthwick, 1957; Downs, 1956).

Traditionally, incandescent lamps have been used for photoperiodic lighting to control crop development because they emitted both $\mathrm{R}$ and FR radiation, were inexpensive, and were commonly available (Craig and Runkle, 2013). However, incandescent lamps have been phased out of production because of their short life span and energy inefficiency (Waide, 2010). Currently, fluorescent and LED lamps are widely available. Fluorescent lamps are not as effective at promoting flowering of LD plants because of their low FR emittance (Whitman et al., 1998). The emergence of LEDs has provided a more energy-efficient, long-lasting lamp option that can vary in spectra, providing the opportunity to optimize the photoperiodic spectrum for various floriculture crops (Owen et al., 2018).

Although photoperiodic flowering and cutting yield and quality of some foliage annuals, including aluminum plant (Pilea cadierei and Pilea 'Moon Valley'), baby rubber plant (Peperomia obtusifolia), coleus (Coleus $\times$ hybridus), Joseph's coat (Alternanthera amoena), English ivy (Hedera helix), and Persian shield (Strobilanthes dyerianus), have been investigated, researchers did not determine the critical photoperiod for these crops nor provide recommendations for nonstock plant producers (Gamrod, 2003; Healy et al., 1980). Therefore, the objectives of this study were 1) to quantify how photoperiod influences growth and development during production and stock plant cutting yield of five foliage annuals and 2) to determine how NI lighting with or without FR radiation influences their growth and development. 


\section{Materials and Methods}

Plant material and greenhouse culture. Vegetative shoot tip cuttings of bloodleaf (Iresine herbstii), Joseph's coat (Alternanthera sp.) 'Brazilian Red Hots' and 'Red Threads', Persian shield (Strobilanthes dyerianus), and variegated potato vine (Solanum jasminoides) were taken from stock plants grown under a $16-\mathrm{h}$ photoperiod and propagated in liner trays. On 11 Oct. 2016 (rep 1) and 11 Jan. 2017 (rep 2), rooted liners were transplanted into $15-\mathrm{cm}$ round $(1.76 \mathrm{~L})$ containers filled with a (by vol.) $70 \%$ peatmoss, $21 \%$ perlite, and $9 \%$ vermiculite substrate (Suremix; Michigan Grower Products Inc., Galesburg, MI) and plants were pinched 2 to 3 weeks later. Plants were irrigated as needed with reverse osmosis water supplemented with $13 \mathrm{~N}-3 \mathrm{P}-15 \mathrm{~K}$ water-soluble fertilizer (mg. $\mathrm{L}^{-1}$ ) 125 nitrogen, 12 phosphorus, 100 potassium, 65 calcium, 12 magnesium, 1.0 iron and copper, 0.5 manganese and zinc, 0.3 boron, and 0.1 molybdenum (MSU Orchid RO Water Special; GreenCare Fertilizers, Inc., Kankakee, IL).

Plants were grown in a glass-glazed greenhouse in East Lansing, MI (lat. $43^{\circ} \mathrm{N}$ ), with exhaust fans, evaporative-pad cooling, radiant steam heating, and supplemental lighting controlled by an environmental control system (Integro 725; Priva North America, Vineland Station, ON, Canada). When the nighttime air temperature on each bench fell under $19.8^{\circ} \mathrm{C}$, a $1500-\mathrm{W}$ electric heater underneath each bench provided supplemental heating. Shielded and aspirated 0.13-mm thermocouples (Type E; Omega Engineering, Stamford, CT) recorded the air temperature and line quantum sensors (SQ-31X-SS; Apogee Instruments, Logan, UT) placed at canopy height recorded the light intensity every $15 \mathrm{~s}$ with means logged hourly by a CR-1000 datalogger (Campbell Scientific, Logan, UT). High-pressure sodium lamps provided a supplemental photosynthetic photo flux density of $77 \pm 13 \mu \mathrm{mol} \cdot \mathrm{m}^{-2} \cdot \mathrm{s}^{-1}$ when the outdoor light intensity was less than $440 \mu \mathrm{mol} \cdot \mathrm{m}^{-2} \cdot \mathrm{s}^{-1}$. The average daily light integral was $12.8 \pm 3.3$ and $13.4 \pm 4.6 \mathrm{~mol} \cdot \mathrm{m}^{-2} \cdot \mathrm{d}^{-1}$, and the average daily temperature was $19.1 \pm 2.3^{\circ} \mathrm{C}$ and $19.4 \pm$ $1.8^{\circ} \mathrm{C}$ during rep 1 and 2 , respectively.

Photoperiod treatments. Plants were placed in photoperiod treatments at transplant. Photoperiods consisted of a truncated 9-h SD photoperiod from 0800 to $1700 \mathrm{HR}$, achieved by opening and closing opaque black cloth over individual greenhouse benches. Each bench was randomly assigned to one of eight photoperiod treatments: 9-h SD or 9-h SD extended by 1 [10 h (1700$1800 \mathrm{HR})], 3$ [12 h (1700-2000 HR)], 4 [13 h (1700-2100 HR)], 5 [14 h (1700-2200 HR)], or $7 \mathrm{~h}$ [16 h (1700-2400 HR)] with four LED lamps containing $\mathrm{R}, \mathrm{W}$, and $\mathrm{FR}$ diodes $(\mathrm{R}: \mathrm{FR}=$ 0.8) (Greenpower flowering lamp DR/W/FR 14W; Philips, Eindhoven, Netherlands) on each bench (Fig. 1). In addition, two treatments consisted of a 9-h day with a 4-h NI from 2200 to $0200 \mathrm{HR}$ from LED lamps containing $\mathrm{R}: \mathrm{W}: \mathrm{FR}$ or $\mathrm{R}: \mathrm{W}$ diodes $(\mathrm{R}: \mathrm{FR}=$ 37.4; Greenpower flowering lamp DR/W

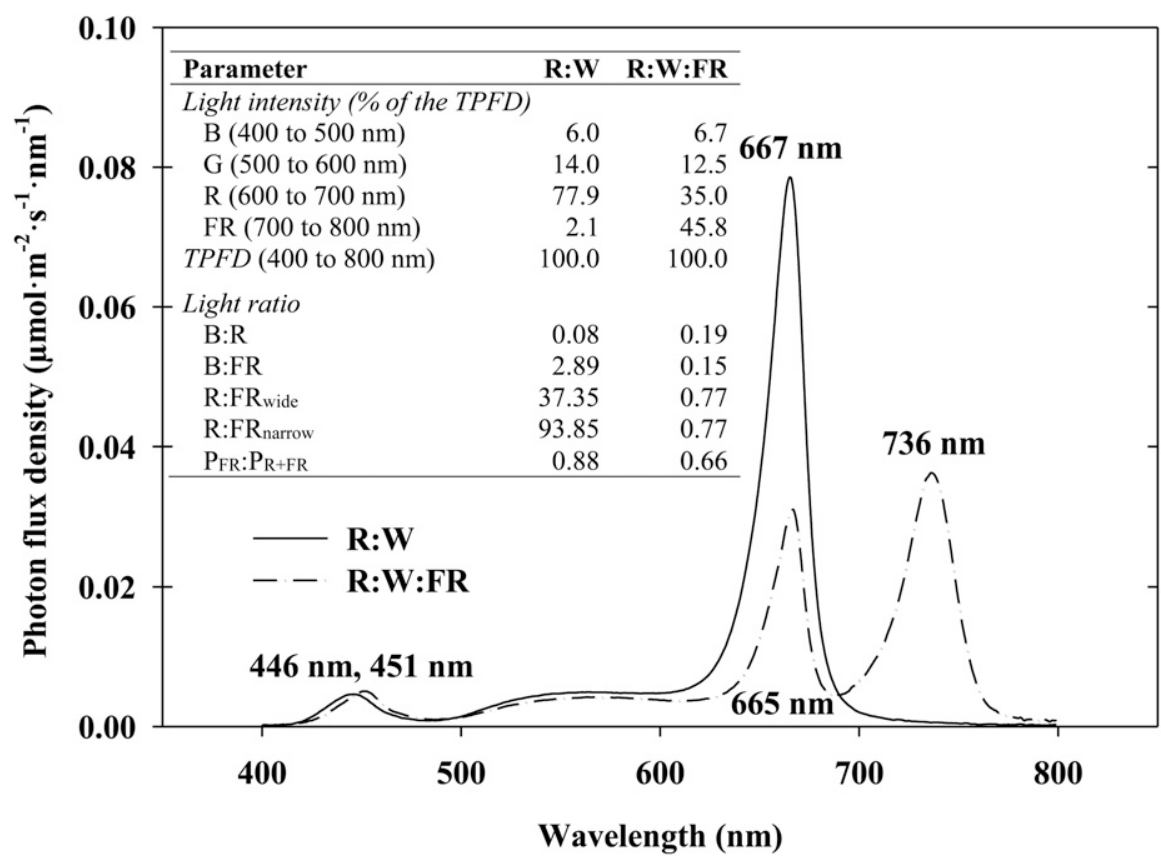

Fig. 1. Spectral distribution, intensity of blue $[B(400-500 \mathrm{~nm})]$, green $[\mathrm{G}(500-600 \mathrm{~nm})]$, red $[\mathrm{R}(600-700$ $\mathrm{nm})]$, and far-red [FR $(700-800 \mathrm{~nm})]$ radiation, total photon flux density $(T P F D)$, light ratio, and estimated phytochrome photoequilibria $\left[\mathrm{P}_{\mathrm{FR}} / \mathrm{P}_{\mathrm{R}+\mathrm{FR}}\right.$ (the proportion of FR-absorbing phytochromes in the pool of R-and FR-absorbing phytochromes; Sager et al., 1988)] of R + white (W) [R+W (solid line)] and $\mathrm{R}+\mathrm{W}+\mathrm{FR}$ light-emitting diode (dashed line) lamps covered with wire mesh. $\mathrm{R}: \mathrm{FR}_{\text {wide }}$ was calculated as 600 to $700 \mathrm{~nm}: 700$ to $800 \mathrm{~nm}$; R:FR narrow was calculated as 655 to $665 \mathrm{~nm}: 725$ to $735 \mathrm{~nm}$.

15W; Philips; Fig. 1). The R:W:FR and R: W NI treatments will henceforth be referred to as NI +FR and NI $-\mathrm{FR}$, respectively. The LED lamps were placed $\approx 1 \mathrm{~m}$ above the bench and covered with aluminum mesh wire (Brite Replacement Screen; Saint-Gobain ADFORS, Grand Island, NY) to reduce the $T P F D$ to $\approx 2 \mu \mathrm{mol} \cdot \mathrm{m}^{-2} \cdot \mathrm{s}^{-1}$ (Fig. 1). The spectral distribution of the LED lamps was measured using a spectroradiometer (PS-200; StellarNet, Inc., Tampa, FL) in four representative locations under each lamp (Fig. 1).

Data collection and analysis. The date the first inflorescence was visible without dissection and the date the first flower opened (anthesis) were recorded for each plant. At flowering, node number, plant height from the surface of the substrate to the tallest growing point, and the widths at the widest point and perpendicular from the widest point were recorded. To provide an integrated measurement of plant size, the GI was calculated $(\mathrm{GI}=$ \{plant height $+[($ diameter $1+$ diameter 2)/2]\}/2) (Krug et al., 2010). For plants that did not flower, the height, widths, and node number were measured 10 weeks after transplant. At this time, the number of vegetative tip cuttings produced by each plant was counted and recorded.

The experiment was organized in a randomized complete block design repeated twice over time. Plants were blocked by photoperiod with 10 experimental units (individual plants) of each species or cultivar (for Joseph's coat) per photoperiod treatment per replication. Data were pooled for all measured characteristics. For each species or cultivar, analysis of variance and Tukey's honestly significant difference analyses were preformed using JMP (version 12.0.1; SAS Institute Inc., Cary, NC).

\section{Results and Discussion}

Flowering. Bloodleaf and Joseph's coat 'Red Threads' developed inflorescences in less than 10 weeks when grown under a photoperiod of $\leq 13 \mathrm{~h}$ and flowered when grown under photoperiods of $\leq 12 \mathrm{~h}$ (Table 1, Fig. 2). Similarly, Joseph's coat 'Brazilian Red Hots' developed inflorescences and flowers when grown under photoperiods of $\leq 12 \mathrm{~h}$. Therefore, the critical photoperiod for bloodleaf and Joseph's coat 'Red Threads' is $13 \mathrm{~h}$ and $12 \mathrm{~h}$ for Joseph's coat 'Brazilian Red Hots'. As photoperiods were reduced from 12 to $9 \mathrm{~h}$, flowering of bloodleaf and Joseph's coat 'Brazilian Red Hots' and 'Red Threads' was hastened by 6,11 , and $7 \mathrm{~d}$, respectively (Table 1). For bloodleaf and Joseph's coat, 14- and 16-h photoperiods and both NI treatments (-FR and +FR) inhibited flowering, as they only developed inflorescences and flowered when the photoperiod was $\leq 13 \mathrm{~h}$; thus, they can be classified as obligate SD plants.

Researchers have demonstrated that $\mathrm{R}$ radiation is as effective as FR radiation at inhibiting flowering of SD plants, including African marigold [(Tagetes erecta) Craig and Runkle, 2013], chrysanthemum [(Chrysanthemum sp.) Cathey and Borthwick, 1957; Craig and Runkle, 2013], cocklebur [(Xanthium strumarium) Borthwick et al., 1952; Downs 1956], dahlia [(Dahlia sp.) Craig and Runkle, 2013], and soybean [(Glycine max) Downs, 1956]. A longer NI duration is needed when FR radiation alone is 
Table 1. Percent of plants with a visible inflorescence and fully open flowers at 10 weeks after transplant and the days to visible inflorescence and days to first open flower for bloodleaf, Joseph's coat 'Brazilian Red Hots' and 'Red Threads', Persian shield, and variegated potato vine grown under 9, 10, 12, 13, 14, $16 \mathrm{~h}$, and $9 \mathrm{~h}+4-\mathrm{h}$ night interruption (NI) + far-red (FR) and -FR photoperiods.

\begin{tabular}{|c|c|c|c|c|}
\hline Photoperiod (h) & $\begin{array}{c}\text { Visible } \\
\text { inflorescences }(\%)\end{array}$ & Flowering $(\%)$ & $\begin{array}{l}\text { Days to visible } \\
\text { inflorescence }\end{array}$ & $\begin{array}{l}\text { Days to first } \\
\text { open flower }\end{array}$ \\
\hline & \multicolumn{4}{|c|}{ Bloodleaf } \\
\hline 9 & 100 & 100 & $32 b^{z}$ & $53 \mathrm{c}$ \\
\hline 10 & 100 & 95 & $34 \mathrm{~b}$ & $56 \mathrm{~b}$ \\
\hline 12 & 100 & 100 & $34 \mathrm{~b}$ & $59 \mathrm{a}$ \\
\hline 13 & 100 & 0 & $60 \mathrm{a}$ & $\infty^{\mathrm{y}}$ \\
\hline 14 & 0 & 0 & $\infty$ & $\infty$ \\
\hline 16 & 0 & 0 & $\infty$ & $\infty$ \\
\hline $9+4 \mathrm{NI}(+\mathrm{FR})$ & 0 & 0 & $\infty$ & $\infty$ \\
\hline \multirow[t]{2}{*}{$9+4$ NI (-FR) } & 0 & 0 & $\infty$ & $\infty$ \\
\hline & \multicolumn{4}{|c|}{ Joseph's coat 'Brazilian Red Hots' } \\
\hline 9 & 100 & 100 & $31 \mathrm{c}$ & $47 \mathrm{c}$ \\
\hline 10 & 100 & 100 & $34 \mathrm{~b}$ & $54 \mathrm{~b}$ \\
\hline 12 & 95 & 95 & $37 \mathrm{a}$ & $58 \mathrm{a}$ \\
\hline 13 & 0 & 0 & $\infty$ & $\infty$ \\
\hline 14 & 0 & 0 & $\infty$ & $\infty$ \\
\hline 16 & 0 & 0 & $\infty$ & $\infty$ \\
\hline $9+4 \mathrm{NI}(+\mathrm{FR})$ & 0 & 0 & $\infty$ & $\infty$ \\
\hline \multirow{2}{*}{$9+4 \mathrm{NI}(-\mathrm{FR})$} & 0 & 0 & $\infty$ & $\infty$ \\
\hline & \multicolumn{4}{|c|}{ Joseph's coat 'Red Threads' } \\
\hline 9 & 100 & 100 & $33 \mathrm{~d}$ & $46 \mathrm{c}$ \\
\hline 10 & 100 & 100 & $36 \mathrm{c}$ & $49 \mathrm{~b}$ \\
\hline 12 & 100 & 100 & $41 \mathrm{~b}$ & $53 \mathrm{a}$ \\
\hline 13 & 95 & 0 & $66 \mathrm{a}$ & $\infty$ \\
\hline 14 & 0 & 0 & $\infty$ & $\infty$ \\
\hline 16 & 0 & 0 & $\infty$ & $\infty$ \\
\hline $9+4 \mathrm{NI}(+\mathrm{FR})$ & 0 & 0 & $\infty$ & $\infty$ \\
\hline \multirow[t]{2}{*}{$9+4 \mathrm{NI}(-\mathrm{FR})$} & 0 & 0 & $\infty$ & $\infty$ \\
\hline & \multicolumn{4}{|c|}{ Persian shield } \\
\hline 9 & 10 & 0 & $-{ }^{\mathrm{x}}$ & - \\
\hline 10 & 85 & 0 & - & - \\
\hline 12 & 10 & 0 & - & - \\
\hline 13 & 40 & 0 & - & - \\
\hline 14 & 35 & 5 & - & - \\
\hline 16 & 15 & 0 & - & - \\
\hline $9+4 \mathrm{NI}(+\mathrm{FR})$ & 20 & 5 & - & - \\
\hline \multirow[t]{2}{*}{$9+4 \mathrm{NI}(-\mathrm{FR})$} & 100 & 0 & - & - \\
\hline & \multicolumn{4}{|c|}{ Variegated potato vine } \\
\hline 9 & 55 & 0 & - & - \\
\hline 10 & 60 & 0 & - & - \\
\hline 12 & 50 & 5 & - & - \\
\hline 13 & 70 & 5 & - & - \\
\hline 14 & 55 & 20 & - & - \\
\hline 16 & 75 & 20 & - & - \\
\hline $9+4 \mathrm{NI}(+\mathrm{FR})$ & 65 & 0 & - & - \\
\hline $9+4 \mathrm{NI}(-\mathrm{FR})$ & 70 & 10 & - & - \\
\hline
\end{tabular}

${ }^{\mathrm{z}}$ Values within columns for each species/cultivar not followed by the same letter are significantly different by Tukey's honestly significant difference test at $P \leq 0.05$.

${ }^{\mathrm{y}}$ Not present by 10 weeks after transplant.

${ }^{\mathrm{x}}$ Not calculated due to inconsistent results.

provided compared with $\mathrm{R}$ radiation alone. The SD plant Chrysanthemum requires 81 min of NI lighting with FR radiation to inhibit flowering, whereas only 16 to 27 min of $\mathrm{R}$ radiation is required (Cathey and Borthwick, 1957). This is a result of $P_{F R}$ falling below the effective threshold more rapidly when $\mathrm{NI}$ is from $\mathrm{FR}$ than from $\mathrm{R}$ radiation (Kasperbauer et al., 1964). In contrast, $\mathrm{R}$ radiation provided by day extension or NI is ineffective at promoting flowering of LD plants, but the addition of FR radiation promotes flowering (Vince et al., 1964; Vince, 1965).

Persian shield and variegated potato vine plants can be classified as day neutral, as plants developed inflorescences when grown under all photoperiods (Table 1). Although flowering did not hinder the growth of variegated
Strobilanthes cernua, a different species in the same genus as Persian shield (Strobilanthes dyerianus), is a pluriannual plant with a 9-year flowering cycle. However, researchers have found that plants also flower in "off" years and those propagated vegetatively flower on a different schedule (Tsukaya et al., 2012). They also noted that, on a given plant, some branches contained flowers whereas others remained vegetative for a longer period. These results correlate with our observation that some plants, propagated from the same stock plant and grown under the same photoperiod, flowered whereas others did not.

Growth. Increasing photoperiod resulted in a height increase of Joseph's coat 'Brazilian Red Hots', as plants grown under a 16-h photoperiod were $19.8 \mathrm{~cm}$ taller than those grown under a 9-h photoperiod (Fig. 3).

It appears that differences in height among treatments may be attributed to flowering. Bloodleaf and Joseph's coat 'Brazilian Red Hots' and 'Red Threads' grown under a 12-h photoperiod were $11.8,12.0$, and $7.1 \mathrm{~cm}$ taller, respectively, than those grown under a 9-h photoperiod (Figs. 2 and 3, Table 1). In contrast, plants that did not flower or took longer to initiate inflorescences (13- to 16-h and NI +FR photoperiods) had similar heights 10 weeks after transplant. In addition, GI tended to follow the same trend as plant height (Fig. 4).

Plants grown under NI -FR were consistently shorter than those grown under NI +FR and most of the R:W:FR day-extension treatments, with the exception of variegated potato vine (Fig. 3). To elaborate, bloodleaf, Joseph's coat 'Brazilian Red Hots' and 'Red Threads', and Persian shield, grown under NI -FR were $16.2,14.7,7.4$, and $12.2 \mathrm{~cm}$ shorter, respectively, than those grown under NI +FR.

The increase in height caused by extension growth may be due to the shade-avoidance response caused by FR radiation. Shading from upper-story canopy plants not only causes a reduction in light intensity but also a shift in spectral composition. Chlorophylls in the leaves absorb $\mathrm{B}$ and $\mathrm{R}$ radiation and reflect or transmit FR radiation. This results in a lower R:FR ratio in the understory. Low R: FR ratios induce a shade-avoidance response, resulting in an increase in stem elongation, leaf area, and apical dominance (Franklin and Whitelam. 2005; Park and Runkle, 2017). Although advantageous under a forest canopy, excess stem elongation is not desired in greenhouse production, where growers aim to produce uniform and compact plants. Therefore, the shade-avoidance response is usually not desired in the production of greenhouse ornamentals.

To produce uniform, compact plants, plant growth regulators are commonly used to lessen extension growth, usually by inhibiting gibberellin synthesis (Currey et al., 2016). However, non-chemical methods of controlling growth such as temperature manipulation through the difference between the day and night temperature can be used (Myster and Moe, 1995). As observed in this study, extension growth can be minimized by manipulating the light spectrum during 


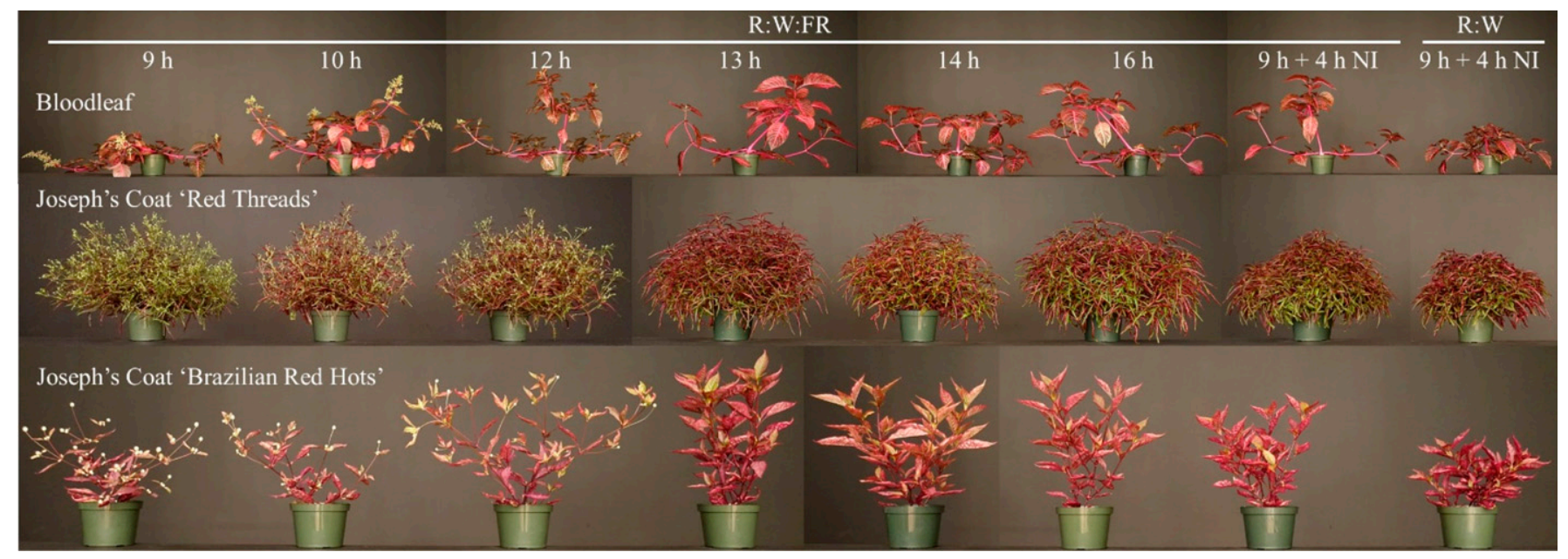

Fig. 2. Growth and development of bloodleaf and Joseph's coat 'Brazilian Red Hots' and 'Red Threads' grown under 9, 10, 12, 13, 14, $16 \mathrm{~h}$, and $9 \mathrm{~h}+4$-h night interruption (NI) + far-red (FR) and -FR photoperiods 10 weeks after transplant. $\mathrm{R}=$ red; $\mathrm{W}=$ white.

photoperiodic lighting. Providing NI lighting without FR radiation is effective in reducing extension growth and inhibiting flowering of SD plants. However, this method would not be effective in promoting flowering of LD plants, as FR radiation is generally required (Runkle and Heins, 2001).

Cutting number. Joseph's coat 'Brazilian Red Hots' and 'Red Threads' grown under 9-, $10-$, or $12-\mathrm{h}$ photoperiods did not yield any vegetative cuttings, mainly due to plants becoming reproductive (Fig. 5, Table 1). The NI +FR treatment produced the greatest cutting yield for 'Red Threads' (404 cuttings per plant). Persian shield under a 9-h photoperiod produced the largest number of vegetative cuttings (10.5 cuttings per plant), although similar harvests were obtained from plants grown under 12-, 14-, 16-h, and NI +FR photoperiods. We hypothesized that, due to the compactness of the NI -FR plants, less radiation would be able to penetrate the canopy, resulting in reduced branching, and therefore, reduced cutting yields. However, this was not the case. Joseph's coat 'Brazilian Red Hots' and variegated potato vine produced a similar number of cuttings regardless of photoperiod, whereas there were minimal differences among vegetative bloodleaf, Joseph's coat 'Red Threads', and Persian shield. Similarly, Healy et al. (1980) reported no differences among coleus, Joseph's coat (A. amoena), peperomia, or pilea grown under fluorescent light with a filter to deliver $\mathrm{R}$ radiation or incandescent light providing more FR radiation. In contrast, the researchers reported that English ivy produced more cuttings when NI was provided by FR radiation than by $\mathrm{R}$ radiation (11.0 and 7.6 cuttings per plant, respectively). Overall, FR radiation promotes extension growth, thus creating a less-compact plant while not widely influencing cutting yield.

\section{Conclusions}

Bloodleaf plant and Joseph's coat 'Brazilian Red Hots' and 'Red Threads' can be classified as obligate SD plants requiring a daylength of

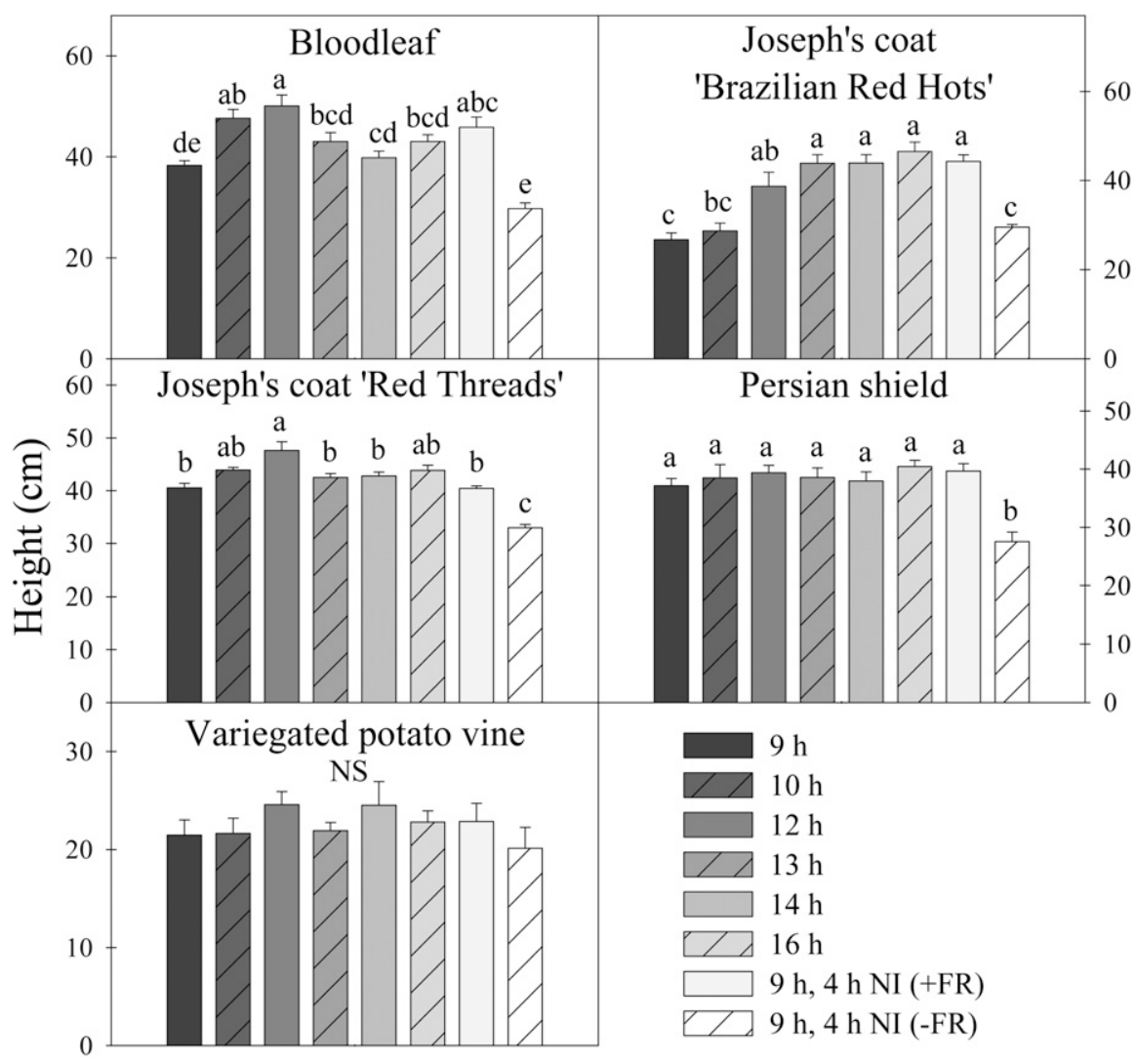

\section{Photoperiod}

Fig. 3. Height of bloodleaf, Joseph's coat 'Brazilian Red Hots' and 'Red Threads', Persian shield, and variegated potato vine at flowering or 10 weeks after transplant for plants that did not flower when grown under 9, 10,12,13,14,16 h, and $9 \mathrm{~h}+4$-h night interruption (NI) + far-red (FR) and -FR photoperiods. Letters indicate mean separation across photoperiods using Tukey's honestly significant difference test at $P \leq 0.05$. Error bars represent SES of the mean.

$\geq 14 \mathrm{~h}$ to inhibit flowering. Height generally increased with increasing daylengths; therefore, if R:W:FR LEDs are used for day extension or NI, a photoperiod of $14 \mathrm{~h}$ can be used to inhibit flowering while minimizing extension growth. LEDs providing $\mathrm{R}: \mathrm{W}$ radiation are equally as effective as those providing $\mathrm{R}: \mathrm{W}: \mathrm{FR}$ radiation at inhibiting flowering when plants are grown under a 4-h NI. Therefore, this study further solidified that FR radiation is not required to control flowering of SD plants, and its elimination in NI lighting can lead to the production of compact foliage plants. 


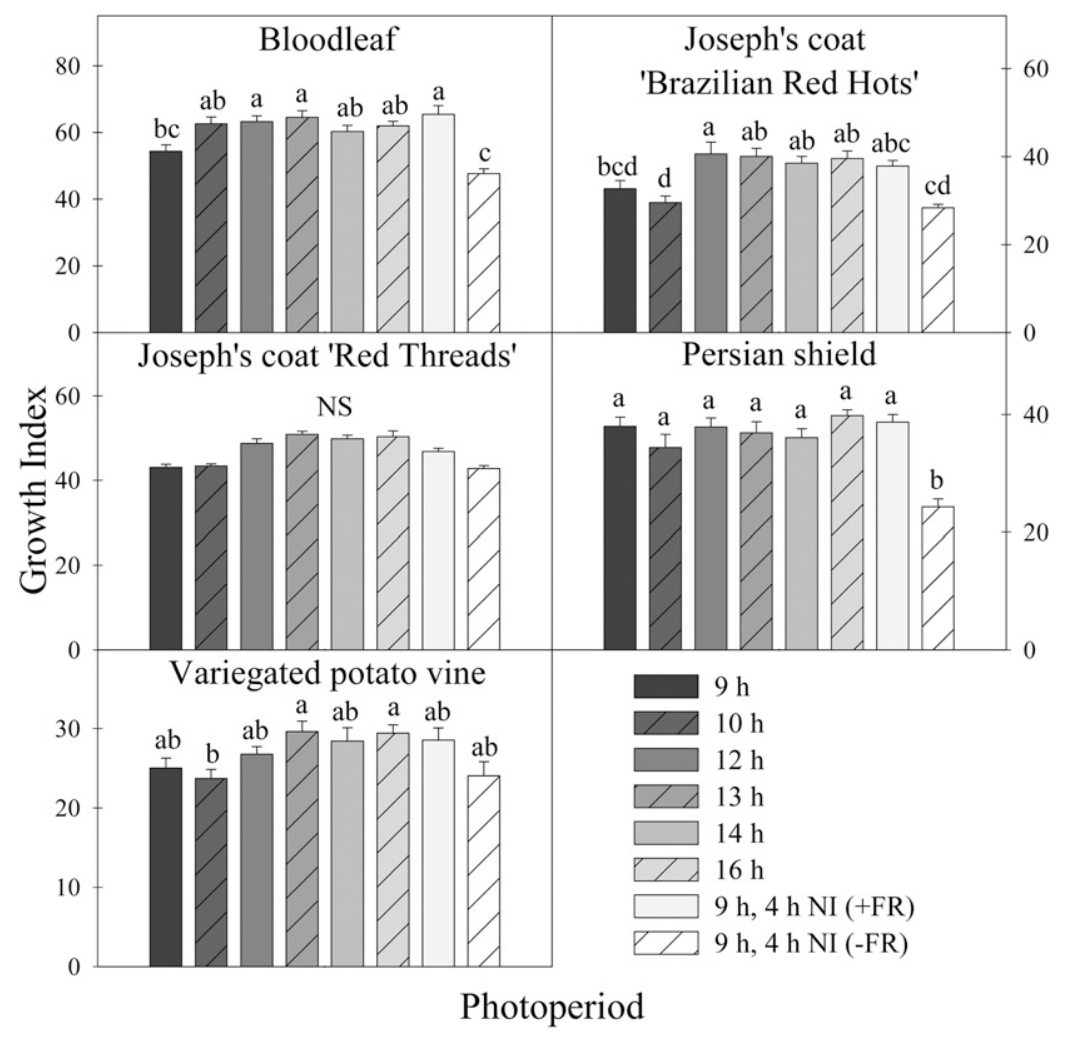

Fig. 4. The growth index $(\mathrm{GI}=$ pplant height $+[($ diameter $1+$ diameter 2$) / 2]\} / 2)$ of bloodleaf, Joseph's coat 'Brazilian Red Hots' and 'Red Threads', Persian shield, and variegated potato vine at flowering or 10 weeks after transplant for plants that did not flower when grown under $9,10,12,13,14,16 \mathrm{~h}$, and $9 \mathrm{~h}+4$-h night interruption (NI) + far-red (FR) and -FR photoperiods. Letters indicate mean separation across photoperiods using Tukey's honestly significant difference test at $P \leq 0.05$. Error bars represent SES of the mean.

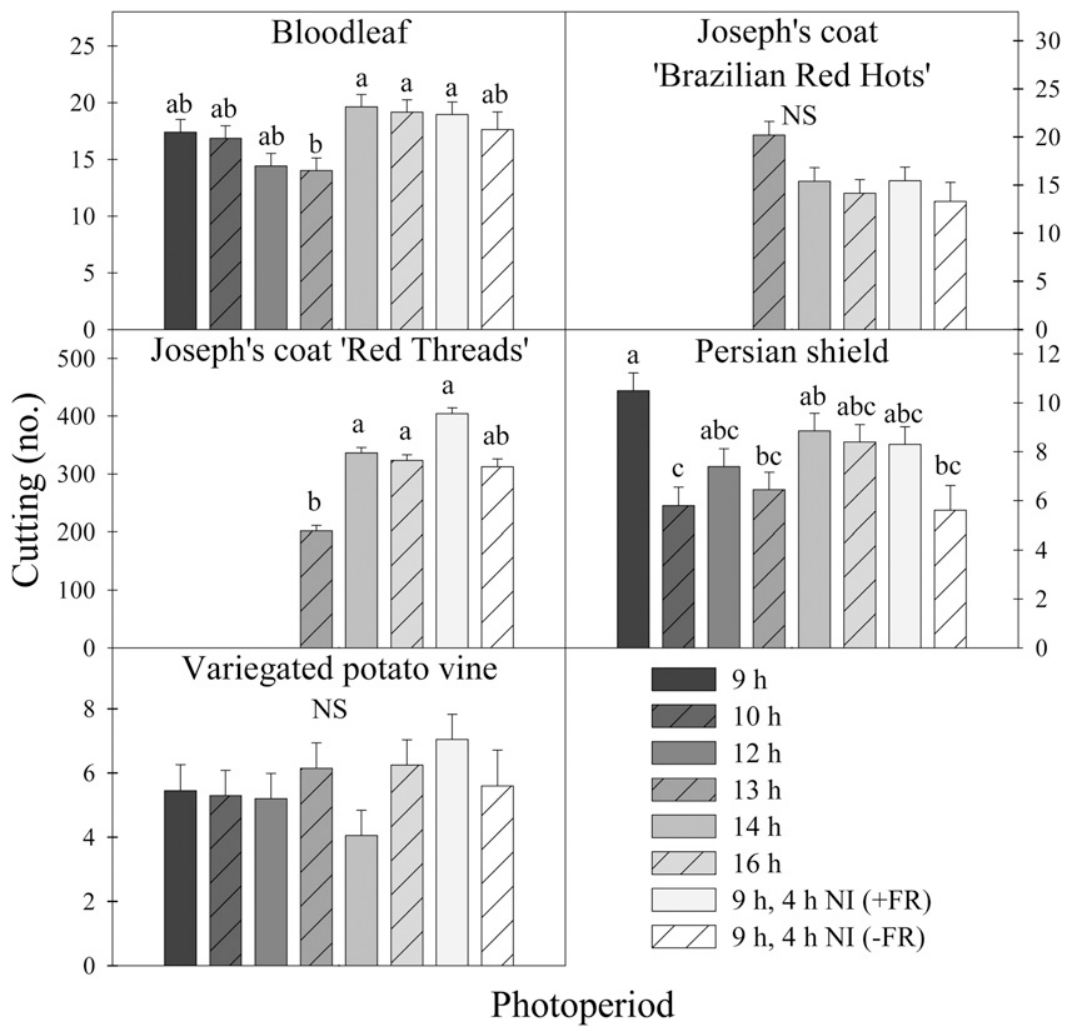

Fig. 5. The cutting yield of bloodleaf, Joseph's coat 'Brazilian Red Hots' and 'Red Threads', Persian shield, and variegated potato vine at flowering or 10 weeks after transplant for plants that did not flower when grown under 9, 10,12,13,14,16 h, and $9 \mathrm{~h}+4$-h night interruption (NI) + far-red (FR) and -FR photoperiods. Letters indicate mean separation across photoperiods using Tukey's honestly significant difference test at $P \leq 0.05$. Error bars represent SES of the mean.

\section{Literature Cited}

Borthwick, H.A., S.B. Hendricks, and M.W. Parker. 1952. The reaction controlling floral initiation. Proc. Natl. Acad. Sci. USA 38:929934.

Cathey, H.M. and H.A. Borthwick. 1957. Photoreversibility of floral initiation in chrysanthemum. Bot. Gaz. 119:71-76.

Craig, D.S. and E.S. Runkle. 2013. A moderate to high red to far-red light ratio from lightemitting diodes controls flowering of short-day plants. J. Amer. Soc. Hort. Sci. 138:167-172.

Craig, D.S. and E.S. Runkle. 2016. An intermediate phytochrome photoequilibria from nightinterruption lighting optimally promotes flowering of several long-day plants. Environ. Expt. Bot. 121:132-138.

Currey, C.J., K.J. Walters, and K.G. McCabe. 2016 Quantifying growth control of lantana cultivars varying in vigor with ancymidol, flurprimidol, paclobutrazol, and uniconazole substrate drenches. HortTechnology 26:320-326.

Downs, R.J. 1956. Photoreversbility of flower initiation. Plant Physiol. 31:279-284.

Franklin, K.A. and G.C. Whitelam. 2005. Phytochromes and shade-avoidance responses in plants. Ann. Bot. 96(2):169-175.

Gamrod, E.E. 2003. Flowering control and production of Strobilanthes dyerianus Mast. (Persian Shield). Virginia Tech, Blacksburg, VA PhD Diss.

Healy, W.E., R.D. Heins, and H.F. Wilkins. 1980 Influence of photoperiod and light quality on lateral branching and flowering of selected vegetatively-propagated plants. J. Amer. Soc. Hort. Sci. 105:812-816.

Kasperbauer, M.J., H.A. Borthwick, and S.B. Hendricks. 1964. Reversion of phytochrome $730(\mathrm{Pfr})$ to $\mathrm{P} 660(\mathrm{Pr})$ assayed by flowering in Chenopodium rubrum. Bot. Gaz. 125(2):7580.

Kim, H.H., R.D. Heins, and W.H. Carlson. 2000 Development and flowering of petunia grown in a far-red deficient light environment. Acta Hort. 580:127-135.

Krug, B.A., B.E. Whipker, I. McCall, and B. Cleveland. 2010. Geranium leaf tissue nutrient sufficiency ranges by chronological age. J. Plant Nutr. 33:339-350.

Lopez, R.G. 2007. Stock plant and propagation photosynthetic daily light integral and storage influence postharvest performance of herbaceous cuttings. Michigan State Univ., East Lansing, MI, PhD Diss.

Myster, J. and R. Moe. 1995. Effect of diurnal temperature alternations on plant morphology in some greenhouse crops - a mini review Scientia Hort. 62(4):205-215.

Nishidate, K., Y. Kanayama, M. Nishiyama, T Yamamoto, Y. Hamaguchi, and K. Kanahama. 2012. Far-red light supplemented with weak red light promotes flowering of Gypsophila paniculata. J. Jpn. Soc. Hort. Sci. 81(2):198203.

Owen, W.G., Q. Meng, and R.G. Lopez. 2018 Promotion of flowering from far-red radiation depends on the photosynthetic daily light integral. HortScience 53:465-471.

Park, Y. and E.S. Runkle. 2017. Far-red radiation promotes growth of seedlings by increasing leaf expansion and whole-plant net assimilation. Environ. Expt. Bot. 136:41-49.

Runkle, E.S. and R.D. Heins. 2001. Specific functions of red, far red, and blue light in flowering and stem extension of long-day plants. J. Amer. Soc. Hort. Sci. 126:275-282.

Sager, J.C., W.O. Smith, L.L. Edwards, and K.L. Cyr. 1988. Use of spectral data to determine 
photosynthetic efficiency and phytochrome photoequilibria. Trans. Amer. Soc. Agr. Eng. 31:1882-1889.

Thomas, B. and D. Vince-Prue. 1997. Photoperiodism in plants. 2nd ed. Academic Press, San Diego, CA.

Tsukaya, H., S. Kakishima, A. Hidayat, J. Murata, and H. Okada. 2012. Flowering phenology of the nine-year plant, Strobilanthes cernua (Acanthaceae). Tropics 20(3):79-85.

USDA. 2016. National Agricultural Statistics Service. Floriculture crops 2015 summary. 20 June 2018. <http://usda.mannlib.cornell.edu/usda/ current/FlorCrop/FlorCrop-04-26-2016.pdf $>$.

van Haeringen, C.J., J.S. West, F.J. Davis, A. Gilbert, P. Hadley, S. Pearson, A.E. Wheldon, and R.G.C. Henbest. 1998. The development of solid spectral filters for the regulation of plant growth. Photochem. Photobiol. 67(4):407-413.

Vince, D., J. Blake, and R. Spencer. 1964. Some effects of wave-length of the supplementary light on the photoperiodic behaviour of the long-day plants, carnation and lettuce. Physiol. Plant. 17(1):119-125.

Vince, D. 1965. The promoting effect of far-red light on flowering in the long day plant Lolium temulentum. Physiol. Plant. 18(2):474-482.

Waide, P. 2010. Phase out of incandescent lamps: Implications for international supply and demand for regulatory compliant lamps. IEA Energy Papers. No. 2010/05, OECD Publishing, Paris.
Walters, K.J., A. Hurt, and R.G. Lopez. 2017. Spice up your container combinations. Greenhouse Mgt. 37(9):36-40.

Whitman, C.M., R.D. Heins, A.C. Cameron, and W.H. Carlson. 1998. Lamp type and irradiance level for daylength extensions influence flowering of Campanula carpatica 'Blue Clips', Coreopsis grandiflora 'Early Sunrise', and Coreopsis verticillata 'Moonbeam'. J. Amer. Soc. Hort. Sci. 123:802-807.

Yuan, M., W.H. Carlson, R.D. Heins, and A.C. Cameron. 1998. Effect of forcing temperature on time to flower of Coreopsis grandiflora, Gaillardia $\times$ grandiflora, Leucanthemum ×superbum, and Rudbeckia fulgida. HortScience 33:663-667. 